\title{
Water vapor transport to material surfaces- Simplified analytical expressions for non-linear material properties
}

\author{
Carl-Eric Hagentoft" \\ Chalmers University of Technology, SE-412 96 Göteborg, Sweden
}

\begin{abstract}
The water vapour transfer between the indoor air and material surfaces is of importance for the moisture balance of the room. It can also be important for the moisture content and durability of the material surface layer such as artefacts in churches and historical buildings. For most building materials the penetration depth due to short time fluctuations, such as diurnal ones, is very limited. For these cases the assumption of semi-infinite analysis gives accurate results even for a rather thin material layer. In the paper, the moisture profile and surface moisture uptake are modelled in detail for isothermal cases and strongly non-linear material properties for the sorption isotherm and vapor permeability. An approximative formula is given for a quite accurate estimate of the moisture up take for a demonstration case with a strongly non-linear material.
\end{abstract}

\section{Problem formulation}

Hygroscopic organic materials, such as wood, are particularly susceptive to changes in the ambient climate. With an increase in RH, wood will adsorb moisture from the ambient air and swell. With a decrease in RH it will desorb moisture and shrink. In a fluctuating climate, constantly moving moisture gradients will develop from the surface and inwards. If the changes in RH are significant, or frequent enough, permanent deformation or damage may occur. This problem coupled to wooden artefacts in churches is analyzed in (Melin et al. 2018). In that article, thin samples of wood with uniform temperature that is changing in time is analyzed. In the report and (Heirstraeten, 2019) the deformation due to changing RH is analyzed further. This paper is a continuation of the work.

The uptake and release of moisture from the surfaces facing the interior climate in rooms is also an area of interest. This moisture interaction between the room and the surfaces can, especially for fast changes, influence the peak values of the moisture content of the indoor air.

It is shown (Hagentoft, 2001) that the penetration depth of the propagating moisture change in a material after step change at the surface is very small. This makes it appropriate

* Corresponding author: carl-eric.hagentoft@chalmers.se 
to study semi-infinite domains and still get the same moisture profile in the surface of the material as for materials with a thickness of say 5 times the penetration depth.

In this article both the moisture profile in semi-infinite materials with strongly nonlinear properties and the moisture uptake at the surface is investigated for step-changes in the ambient climate during isothermal conditions. In the study the effect of surface resistances and hysteresis is neglected.

\section{The mathematical problem}

Using the humidity by volume $v\left(\mathrm{~kg} / \mathrm{m}^{3}\right)$ the moisture flow, $g\left(\mathrm{~kg} / \mathrm{m}^{2} / \mathrm{s}\right)$, in the material is given by:

$g=-\delta(\varphi) \frac{\partial v}{\partial x}$

Here, the vapour permeability is given by $\delta(\varphi)\left(\mathrm{m}^{2} / \mathrm{s}\right)$, and it depends on the relative humidity $\varphi(-)$.

The moisture balance equation reads:

$-\frac{\partial}{\partial x}(g)=\frac{\partial w}{\partial t}$

Here, $w\left(\mathrm{~kg} / \mathrm{m}^{3}\right)$, is the moisture content in the material. It depends on the relative humidity. The slope of the sorption isotherm is introduced:

$$
\xi(\varphi)=\frac{\partial w}{\partial \varphi}
$$

The relative humidity is defined from:

$\varphi=\frac{v}{v_{s}(T)}$

Here, $T\left({ }^{\circ} \mathrm{C}\right)$ will be the constant temperature, and $v_{s}\left(\mathrm{~kg} / \mathrm{m}^{3}\right)$ is the humidity by volume at saturation. A function for the moisture diffusivity $a\left(\mathrm{~m}^{2} / \mathrm{s}\right)$ is also introduced:

$a(\varphi, T)=\frac{\delta(\varphi)}{\xi(\varphi)} \cdot v_{s}(T)$

Combining the moisture balance equation (2) with (1) and (3-5):

$f(\varphi) \cdot\left(\frac{\partial \varphi}{\partial x}\right)^{2}+\frac{\partial^{2} \varphi}{\partial x^{2}}=\frac{1}{a(\varphi, T)} \frac{\partial \varphi}{\partial t} \quad f(\varphi)=\frac{d \delta(\varphi)}{d \varphi} / \delta(\varphi)=\frac{\delta^{\prime}}{\delta(\varphi)}$

In order to find a dimensionless solution, the following transformation is introduced:

$s=\frac{x}{\sqrt{a_{0} t}} \quad a_{0}=\frac{\delta\left(\varphi_{0}\right)}{\xi\left(\varphi_{0}\right)} v_{s}(T)=\frac{\delta_{0}}{\xi_{0}} v_{s}(T)$

We get:

$$
\begin{gathered}
-\frac{\partial^{2} \varphi}{\partial s^{2}}=g(\varphi) \frac{\partial \varphi}{\partial s} \frac{s}{2}+f(\varphi) \cdot\left(\frac{\partial \varphi}{\partial s}\right)^{2} \\
f(\varphi)=\frac{\delta^{\prime}}{\delta(\varphi)} \quad g(\varphi)=\frac{a_{0}}{a}=\frac{\delta_{0}}{\xi_{0}} \frac{\xi(\varphi)}{\delta(\varphi)}
\end{gathered}
$$

Here, both $f$ and $g$ are dimensionless functions depending on the RH only. The boundary condition at $x=0$ and the initial conditions are transformed according to: 


$$
\begin{aligned}
& \varphi(x=0)=\varphi_{b} \Rightarrow \varphi(s=0)=\varphi_{b} \\
& \varphi(t=0)=\varphi_{i} \Rightarrow \varphi(s=\infty)=\varphi_{i}
\end{aligned}
$$

By combining (1), with $(4)$ and $(7,9)$, the moisture flow $r\left(\mathrm{~kg} / \mathrm{m}^{2} / \mathrm{s}\right)$ in to the material at the surface reads:

$$
\cdot \quad-\left.\frac{s_{s}(T)}{\overline{u_{0} t}} \cdot \frac{\partial \varphi}{\partial s}\right|_{s=0}=-\left.\sqrt{\frac{\delta_{b}^{2} v_{s}(T) \xi_{0}}{\delta_{0} t}} \cdot \frac{\partial \varphi}{\partial s}\right|_{s=0} \quad \delta_{b}=\delta\left(\varphi_{b}\right)
$$

The accumulated moisture uptake is:

$$
m=\left.\int_{0}^{t} i \quad \Gamma_{t} \cdot \sqrt{\frac{\delta_{b}^{2} v_{s}(T) \xi_{0}}{\delta_{0}}} \cdot \frac{\partial \varphi}{\partial s}\right|_{s=0}
$$

For materials with $f=0$ and $g=1$, e.g. materials with constant vapor permeability and constant slope of the sorption curve, we have the following equation to be solved:

$\frac{\partial^{2} \varphi}{\partial s^{2}}=-\frac{\partial \varphi}{\partial s} \frac{s}{2} \quad a_{0}=\frac{\delta_{0}}{\xi_{0}} \cdot v_{s}(T)$

The solution is well known:

$$
\varphi(s)=\varphi_{i}+\left(\varphi_{b}-\varphi_{i}\right) \cdot \operatorname{erfc}\left(\frac{s}{2}\right)\left(=\varphi_{i}+\left(\varphi_{b}-\varphi_{i}\right) \cdot \operatorname{erfc}\left(\frac{x}{\sqrt{4 a_{0} t}}\right)\right)
$$

We have:

$$
\left.\frac{\partial \varphi}{\partial s}\right|_{s=0}=-\left(\varphi_{b}-\varphi_{i}\right) \cdot \sqrt{\frac{1}{\pi}}
$$

This results in the following moisture flow:

$$
\begin{aligned}
& \left.i \quad \jmath_{i}\right) \cdot \sqrt{\frac{\delta_{b}^{2} v_{s}(T) \xi_{0}}{\delta_{0} \pi t}} \\
& m=\left(\varphi_{b}-\varphi_{i}\right) \cdot \sqrt{\frac{\delta_{b}^{2} v_{s}(T) \xi_{0}}{\delta_{0} \pi}} \cdot 2 \sqrt{t}
\end{aligned}
$$

\section{Numerical solution technique}

Equation (8) is a non-linear ordinary differential equation (ODE). It can, for instance, be solved numerically using a Matlab solver for systems of ODE by first formulate it as follows:

$$
\left\{\begin{array}{l}
y_{1}(s)=\varphi(s) \\
y_{2}(s)=\frac{d \varphi(s)}{d s}
\end{array}\right.
$$




$$
\left\{\begin{array}{l}
\frac{d y_{1}}{d s}=\left[\frac{d \varphi(s)}{d s}\right]=y_{2} \\
\frac{d y_{2}}{d s}=\left[\frac{d^{2} \varphi}{d s^{2}}=-g \cdot \frac{d \varphi}{d s} \frac{s}{2}-f \cdot\left(\frac{d \varphi}{d s}\right)^{2}\right]=-y_{2} \cdot\left(g\left(y_{1}\right) \cdot \frac{s}{2}+f\left(y_{1}\right) \cdot y_{2}\right)
\end{array}\right.
$$

When the ODE-solver is used it requires value for:

$\left\{\begin{array}{l}y_{1}(0)=\varphi(0)=\varphi_{b} \\ y_{2}(0)=\left.\frac{\partial \varphi}{\partial s}\right|_{s=0}\end{array}\right.$

The value $y_{2}(0)$ is not known directly. However, it is found by finding the solution that meets the requirement (10), i.e. $y_{1}(\infty)=\varphi_{i}$, starting with an initial guess using (15). The Matlab code, using the function fzero, is given in the appendix below.

\section{Example}

A generic material with an assumed same breaking point for both the vapor permeability and the sorption isotherm at $\tilde{\varphi}$ is used in the example:

$$
\begin{aligned}
\delta(\varphi) & = \begin{cases}\delta_{0} & \varphi<\tilde{\zeta} \\
\delta_{0}+A \cdot(\varphi-\tilde{\zeta} & \sim\end{cases} \\
w(\varphi) & = \begin{cases}\xi_{0} \cdot \varphi & \varphi<\tilde{\zeta} \\
\xi_{0} \cdot \varphi+B \cdot(\varphi-\tilde{\zeta} & \sim\end{cases}
\end{aligned}
$$

For $f$ and $g$ we get:

$$
\begin{aligned}
& f(\varphi)= \begin{cases}0 & \varphi<\tilde{\zeta} \\
\frac{2 A(\varphi-\tilde{\zeta}}{\delta_{0}+A \cdot(\varphi-\tilde{\zeta}} & \varphi \geq \tilde{\zeta}\end{cases} \\
& g(\varphi)= \begin{cases}1 & \varphi<\tilde{\zeta} \\
\frac{\xi_{0}+2 B(\varphi-\tilde{\zeta}}{\xi_{0}} \delta_{0}+A \cdot \overline{\bar{\zeta}_{0}} & \varphi \geq \tilde{\zeta}\end{cases}
\end{aligned}
$$

The following case will be used (approximately wood); $\xi_{0}=100 \mathrm{~kg} / \mathrm{m}^{3}, \delta_{0}=10^{-6} \mathrm{~m}^{2} / \mathrm{s}$, $A=10^{-5} \mathrm{~m}^{2} / \mathrm{s}, \mathrm{B}=500 \mathrm{~kg} / \mathrm{m}^{3}$ with the breaking point $\tilde{\varphi}$ is analyzed in detail. The boundary and initial $\mathrm{RH}$ are: $\varphi_{b}=0.9, \varphi_{i}=0.3$. In the calculation later, for the moisture flow, the temperature $\mathrm{T}=20{ }^{\circ} \mathrm{C}$ is assumed. Figure 1 shows the vapor permeability and the sorption isotherm: 

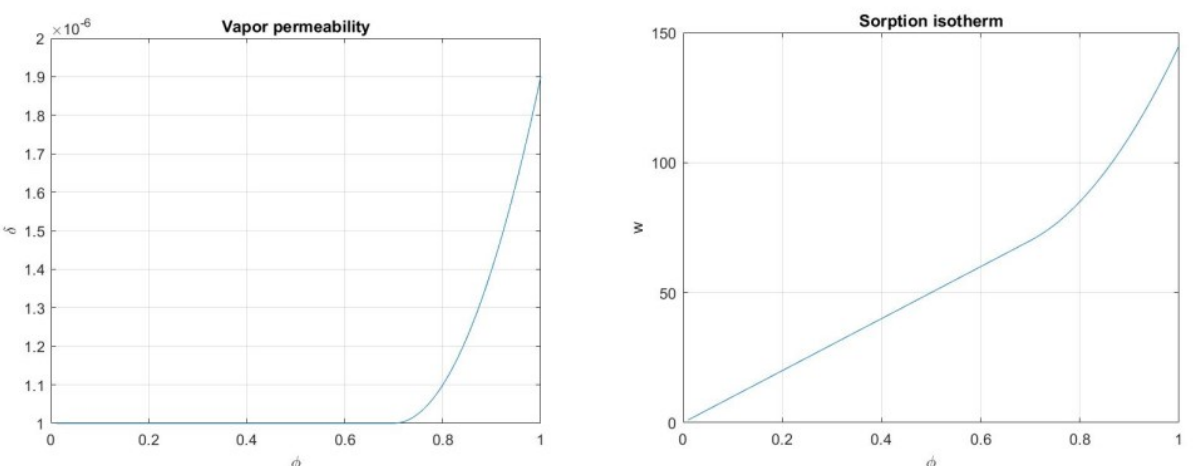

Fig. 1. The vapor permeability $\delta\left(\mathrm{m}^{2} / \mathrm{s}\right)$ and the sorption isotherm $w\left(\mathrm{~kg} / \mathrm{m}^{3}\right)$ for the considered material.

Figure 2 shows the functions $f$ and $g$ for the considered case and the calculated relative humidity:
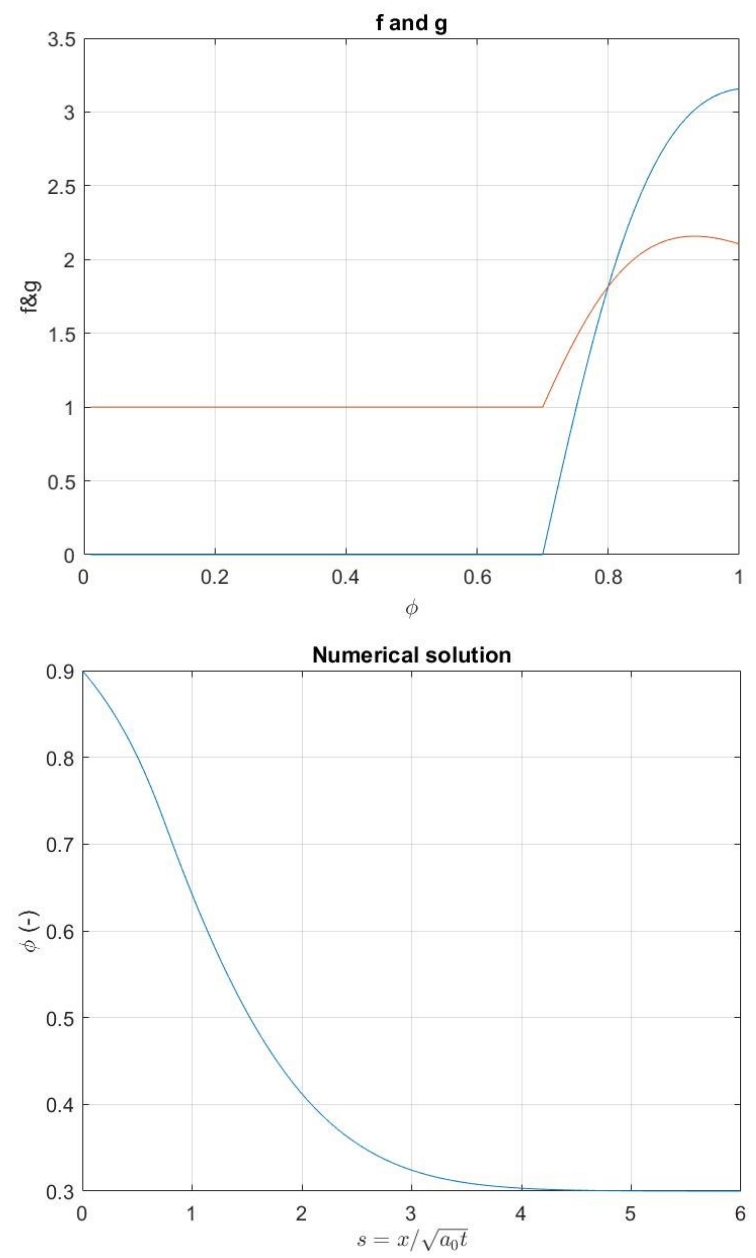
Fig. 2. The functions $f(-)$ and $g(-)$ for the considered case and the numerically calculated relative humidity in the material as a function of the dimensionless number $s$ (7), where $a_{0}$ is defined by (13).

Figure 3 shows some other results with different constants $\mathrm{A}$ and $\mathrm{B}$. The thick line represents the basic case with $\left(A=10^{-5} \mathrm{~m}^{2} / \mathrm{s}, \mathrm{B}=500 \mathrm{~kg} / \mathrm{m}^{3}\right)$. The other curves give solutions for other sets of $\mathrm{A}$ and $\mathrm{B}$.

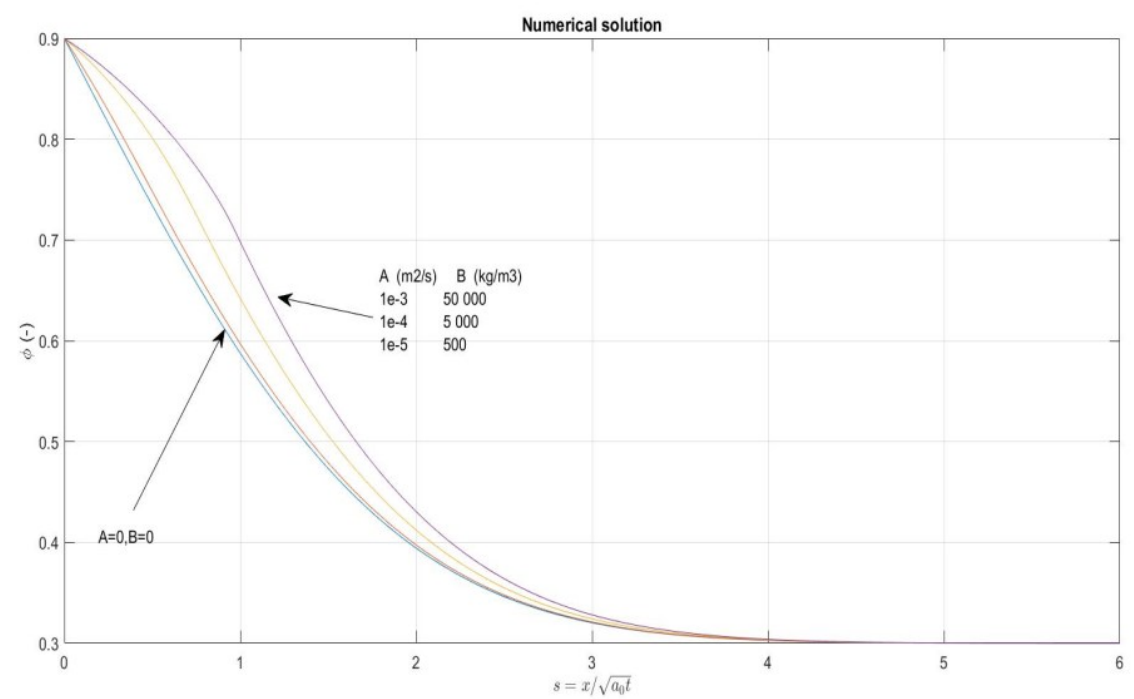

Fig. 3. Numerically calculated relative humidity as a function of the dimensionless number $s$, for varying sets of $\mathrm{A}$ and $\mathrm{B}$.

Table 1 gives the calculated moisture flow into the material (11-12) and the slope of the relative humidity at the surface.

Table 1. The current moisture uptake and the accumulated one, at $20^{\circ} \mathrm{C}$, are given for the time points: $1 \mathrm{~h}, 24 \mathrm{~h}, 2$ days, 1 week, 1 month. $\left(\xi_{0}=100 \mathrm{~kg} / \mathrm{m}^{3}, \delta_{0}=10^{-6} \mathrm{~m}^{2} / \mathrm{s}\right)$.

$A=0 \mathrm{~m}^{2} / \mathrm{s}, \mathrm{B}=0 \mathrm{~kg} / \mathrm{m}^{3},\left.\frac{\partial \varphi}{\partial s}\right|_{s=0}=-1 / \sqrt{\pi} \approx-0.3385$
\begin{tabular}{|l|l|l|l|l|l|}
\hline Time & $1 \mathrm{~h}$ & $2 \mathrm{~h}$ & 2 days & 1 week & 1 month \\
\hline$\dot{r}\left(\mathrm{~g} / \mathrm{m}^{2} / \mathrm{h}\right)$ & 26.7 & 18.9 & 3.85 & 2.06 & 0.993 \\
\hline$m\left(\mathrm{~g} / \mathrm{m}^{2}\right)$ & 53.4 & 75.5 & 370 & 692 & 1433 \\
\hline
\end{tabular}

$A=10^{-5} \mathrm{~m}^{2} / \mathrm{s}, \mathrm{B}=500 \mathrm{~kg} / \mathrm{m}^{3},\left.\frac{\partial \varphi}{\partial s}\right|_{s=0}=-0.2649$

\begin{tabular}{|l|l|l|l|l|l|}
\hline Time & $1 \mathrm{~h}$ & $2 \mathrm{~h}$ & 2 days & 1 week & 1 month \\
\hline$\dot{r}\left(\mathrm{~g} / \mathrm{m}^{2} / \mathrm{h}\right)$ & 29.2 & 20.7 & 4.22 & 2.26 & 1.09 \\
\hline$m\left(\mathrm{~g} / \mathrm{m}^{2}\right)$ & 58.5 & 82.7 & 405 & 758 & 1569 \\
\hline
\end{tabular}

$A=10^{-4} \mathrm{~m}^{2} / \mathrm{s}, \mathrm{B}=5000 \mathrm{~kg} / \mathrm{m}^{3},\left.\frac{\partial \varphi}{\partial s}\right|_{s=0}=-0.1457$

\begin{tabular}{|l|l|l|l|l|l|}
\hline Time & $1 \mathrm{~h}$ & $2 \mathrm{~h}$ & 2 days & 1 week & 1 month \\
\hline
\end{tabular}




\begin{tabular}{|l|l|l|l|l|l|}
\hline$\dot{r}^{\cdot}\left(\mathrm{g} / \mathrm{m}^{2} / \mathrm{h}\right)$ & 57.5 & 40.6 & 8.30 & 4.43 & 2.14 \\
\hline$m\left(\mathrm{~g} / \mathrm{m}^{2}\right)$ & 115 & 163 & 796 & 1490 & 3084 \\
\hline
\end{tabular}

$A=10^{-3} \mathrm{~m}^{2} / \mathrm{s}, \mathrm{B}=50000 \mathrm{~kg} / \mathrm{m}^{3},\left.\frac{\partial \varphi}{\partial s}\right|_{s=0}=-0.1141$
\begin{tabular}{|l|l|l|l|l|l|}
\hline Time & $1 \mathrm{~h}$ & $2 \mathrm{~h}$ & 2 days & 1 week & 1 month \\
\hline$\dot{r}\left(\mathrm{~g} / \mathrm{m}^{2} / \mathrm{h}\right)$ & 369 & 261 & 53.2 & 28.5 & 13.7 \\
\hline$m\left(\mathrm{~g} / \mathrm{m}^{2}\right)$ & 738 & 1043 & 5111 & 9562 & 19796 \\
\hline
\end{tabular}

The slope of the relative humidity at the surface, with respect to the non-dimensional variable $s$, does not vary much for the considered cases in Table 1. It varies between $-1 / \sqrt{\pi}$ and -0.1141 . This means that we can estimate the moisture flow quite well using formulas (11-12) and the interval of the slope for the considered example for the considered domain.

$\left.\sqrt{\frac{\delta_{b}^{2} v_{s}(T) \xi_{0}}{\delta_{0} t}} \cdot 0.1141 \leq \frac{i}{\left(\varphi_{b}\right.}-\varphi_{i}\right)-V \frac{\overline{i_{b}^{2} v_{s}(T) \xi_{0}}}{\delta_{0} t} \frac{1}{\sqrt{\pi}}$

Further investigations will show how the formulas can be further simplified for estimating moisture fluxes more generally.

\section{Conclusions}

A methodology is described by which the moisture profile inside a semi-infinite domain of a strongly nonlinear material can be calculated. The necessary code, here described in Matlab, is short, efficient and accurate. The formulation is based on one non-dimensional parameter that contains both time and space. Formulas for the moisture flow rate and the accumulated moisture uptake is given. A formula is outlined that gives a quite accurate estimation of the interval of the moisture uptake.

\section{References}

1. M. Heirstraeten. Master Thesis: Mechanical deformation of wood panels due to varying climate - Numerical simulations. Building Technology, Chalmers University of Technology (2019)

2. Charlotta Bylund Melin, Carl-Eric Hagentoft, Kristina Holl, Vahid M. Nik and Ralf Kilian. Simulations of Moisture Gradients in Wood Subjected to Changes in Relative Humidity and Temperature Due to Climate Change. Journal of Geosciences, 8, 378 (2018)

3. C.-E.Hagentoft C E 2001, Textbook: Introduction to Building Physics.

Studentlitteratur, ISBN 91-44-01896-7 (2001) 


\section{Appendix - Matlab code}

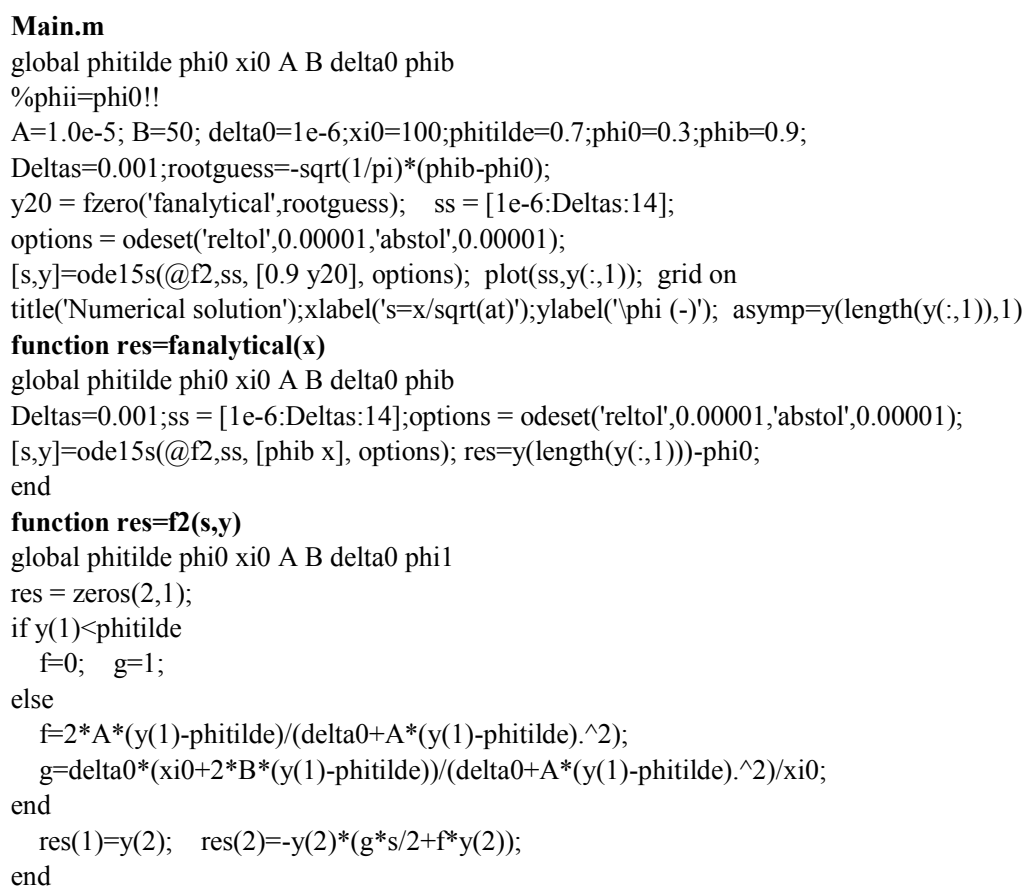

